\title{
LA CONSTRUCCIÓN DE UNA IDENTIDAD: EL MUNDO INDÍGENA EN LA LITERATURA INDEPENDENTISTA (LA LIRA ARGENTINA)
}

\author{
ELENA DE LORENZO ÁLVAREZ
}

Somos los que fuisteis, seremos los que sois

Canto espartano

1

Rafael Gutiérrez Girardot, La formación del intelectual hispanoamericano en el siglo XIX, Maryland, University of Maryland at College Park (Latin American Studies Center Series, $\mathrm{n}^{\circ}$ 3), 1990, 72 págs., la cita en la pág. 15.

2

Juan Bautista Alberdi, "Observaciones sobre el Certamen poético celebrado en Montevideo en 1841 », en Florencio Varela, Informe de la Comisión Clasificadora del Certamen poético de Mayo, Montevideo, Imprenta Constitucional del P. P. Olave, 25 de mayo de 1841, págs. I-XVIII; informe y observaciones están recogidos en J. B. Alberdi, Obras completas, vol. II, Buenos Aires, 1886. Estos dos textos son el eje de la polémica sobre el momento del nacimiento de una literatura "argentina», esto es, sobre si podía haber una literatura americana durante la colonia, lo que Alberdi contempla y Varela re-

La construcción de una identidad: el mundo indígena en la literatura independentista (La Lira Argentina) ELENA DE LORENZO ÁLVAREZ
Todo ilustrado siente hacia la res publica una responsabilidad que lo lleva a realizarse atendiendo a algún perfil del «amigo de la patria». Este patriotismo ilustrado aboca al intelectual americano de principios del siglo XIX, al «hombre de letras-político»', a traducir literariamente el abandono de las estructuras de pertenencia a la comunidad del mundo colonial, a legitimar los actos independentistas y a gestar la constitución imaginaria de una nueva identidad, labor que sería un «acto de americanidad» y la patriótica contribución de los poetas a las nuevas naciones.

La imbricación de la literatura y la política, que luego se volcará hacia el campo del ensayo, se evidencia en estos años significativamente en unas formas poéticas que se corresponden con la poesía filosófica de la Ilustración que surge

chaza. Sobre estas cuestiones véase Emilio Carilla, Hispanoamérica y su expresión literaria. Caminos del americanismo, Buenos Aires, Editorial Universitaria de Buenos Aires (Eudeba: Colección América / Temas), 1969, págs. 28-29. Para las implicaciones políticas de estos enfrentamientos litera- rios y la matización de las posiciones de los supuestamente «neoclásicos» y «románticos» véase Teodosio Fernández, «Introducción» a Teoría y crítica de la emancipación hispanoamericana, Alicante, Generalitat Valenciana, Instituto de Cultura Juan Gil-Albert, 1997 , págs. 13-40. en los últimos decenios del xviII: de la mano de un grupo de «neoclásicos heterodoxos»-Trigueros, Jovellanos, Meléndez, Quintana, Gallego, Cienfuegos- se busca, no sólo una renovación estética conseguida ya por el movimiento rococó y el «neoclasicismo ortodoxo» -los Moratín, Cadalso, García de la Huerta, Forner-, sino también una innovación temática que adecue la literatura a su contemporaneidad atendiendo a la noción axial de progreso encomiando reformas que se encaran, dibujando las virtudes civiles, proponiendo otras relaciones sociales, esbozando los males que la patria enfrenta...

En el ámbito hispanoamericano los poetas, «independientes en política, colonos en literatura» ${ }^{2}$ como los definió Juan Bautista Alberdi refiriéndose a la poesía argentina, han de responder a su propio desafío renovador: partir de referentes lingüísticos y literarios consagrados por la poesía filosófica -esa «colonización» literaria de la que se habla desde el punto de vista romántico y americano, que es la intertextualidad experimental que ampara una imitatio neoclásica en auge en toda Europa-, y adecuarlos a su propio contexto, para que expresen y alienten la experiencia del 
nacimiento de una patria justificando, legitimando y prestigiando los actos independentistas-motivados por la presión impositiva y la frustración de las expectativas de los españoles americanos, y alentados por una elite imbuida de actitudes ilustradas y formada en la metrópoli3-, y dibujando una nueva identidad que arropara intelectualmente al nuevo estado que se forjaba en el ámbito político pero no proporcionaba aún a sus ciudadanos vínculos institucionales ni formas de gobierno estables.

La lira argentina o Colección de poesía patriótica ${ }^{4}$ destaca entre la poesía independentista hispanoamericana como un corpus verdaderamente excepcional, dado que se trata de una recopilación de 131 poemas publicados en 1824, que evidencia la mediación explícita de la esfera política en la constitución de un canon literario que la exprese: la compilación no responde a una construcción crítica actual, sino que el corpus es el resultado de sucesivas propuestas gubernamentales - desde la del Congreso de las Provincias en 1816 hasta la de Rivadavia en 1822-, es costeada con el «fondo reservado» del gobierno -el «fondo de guerra» de independencia- y entendida como un «monumento de los más propios a celebrar el aniversario de la declaración de nuestra triunfante independencia tan enérgicamente pronunciada ${ }^{5}$-un monumento similar aunque posterior es el Parnaso oriental, la primera antología poética del Uruguay (1835-1837) solapamiento del ámbito político y el circuito literario también se comprueba en la apreciación de este corpus como germen de una literatura propia en el artículo de Juan Cruz Varela significativamente titulado «Literatura nacional» (1828)7 dicha imbricación se palpa además en la ordenación de los poemas, que atiende a la cronología excepto, como señala el editor de 1823, en el caso de la Marcha patriótica (1813), que abre el volumen y conmemora la independencia, y El triunfo argentino (1808), que cierra el libro celebrando la victoria de 1807 frente a los ingleses ${ }^{8}$ : la voluntad política disloca el trazado cronológico concediendo a estos dos poemas de Vicente López y Planes un privilegiado lugar textual en virtud de su correspondencia simbólica con el imaginario independentista -las invasiones inglesas del Río de la Plata en el marco de las guerras napoleónicas (1806-1807), que remiten al tiempo de pertenencia a la corona, y la

Revolución de Mayo (25 de mayo de 1810) y la Independencia (9 de Julio de 1816)-; tales intersecciones político-literarias fueron perfectamente advertidas por el Ministro de Policía de la Francia napoleónica, donde se imprimió la obra, que expulsó del país a quienes llevaban los 2.000 ejemplares de la Lira hasta Buenos Aires, por ser «autores de una obra escandalosa en que se trataba inicuamente $y$ echaba por tierra las coronas, principalmente la de Fernando, y la religión» ${ }^{9}$.

Los poetas de mayo, de la revolución o de la independencia, que de todas estas formas se les llama ${ }^{10}$, enfrentaron el reto de alentar y legitimar el nacimiento de una patria, la primera independizada del poder español en 1810, esbozando para ella una identidad propia. La elaboración de un «ser nacional»

3

Sobre esta interpretación véase François López, «llustración $e$ independencia hispanoamericana. Reflexiones sobre una tradición historiográfica», en Homenaje a Noël Salomón. llustración española e independencia americana, Barcelona, Universidad Autónoma de Barcelona, 1979, págs. 289-297.

4

La lira argentina o colección de las piezas poéticas dadas a luz en Buenos Aires durante la guerra de su independencia, edición crítica, estudio y notas por Pedro Luis Barcia, Buenos Aires, Academia Argentina de Letras (Serie Clásicos Argentinos, XV), 1982. La colección no pretendía ser exhaustiva: otros poemas no recogidos en ella pueden verse en Óscar F. Urquiza Almandoz, "La poesía», en La cultura de Buenos Aires a través de la prensa periódica desde 1810 a 1820, Buenos Aires, Eudeba, 1972, págs. 399-477.
5

Registro Oficial, Buenos Aires (16 de julio de 1822), libro II, $\mathrm{n}^{\circ}$ 20, págs. 264-265. Apud Pedro Luis Barcia, «Estudio preliminar», en La lira argentina, op. cit., págs. XII-XIII.

6

El Parnaso Oriental o guirnalda poética de la República Uruguaya, Buenos Aires, La Libertad / Montevideo, Imprenta de la Caridad, 1835, 2 tomos, 290+293 págs.; Luciano Lira (ed.), Montevideo, Talleres Gráficos Barreiro y Ramos, 1981, 3 vols.

\section{7}

Juan Cruz Varela, «Literatura nacional», El Tiempo. Diario político, literario y mercantil (Buenos Aires), 14 de junio de $1828, n^{\circ} 36$, pág. 2 . Sigue en los nos $44,49,51$, 68. Para un análisis del artículo véase Félix Weimberg, "Juan Cruz Varela, crítico de la literatura argentina», Boletín de literatura argenfina (Córdoba, UNC), agosto de 1964, I, nº 1, págs. 29-63.
L A

\section{LIRA ARGENTINA,}

Ó CORECCLON

DE LAS PIEZAS POETICAS,

DADASA LU:

N BUENOS-AYRES

DURATE LA GUERRA

BUENOS-AYRES.

1824 .
8

La lira argentina, op. cit., pág. 8.

9

El argentino (Buenos Aires), 24 de diciembre de 1824, $\mathrm{n}^{\circ}$ 2; apud Rafael Alberto Arrieta, «En torno a La Lira Argentina», Boletín de la Academia Argentina de Letras, julio-diciembre de 1938 , t. VI, nos 23-24, págs. 422-426; también en Pedro Luis Barcia, "Estudio preliminar», La lira argentina, op. cit., pág. XIV.

10

«Poetas de la revolución» los llama Arturo Giménez Pastor en Estudios de literatura argentina, I. Los poetas de la revolución, Buenos Aires, Librería de García Santos, 1917; de «literatura de mayo" o "poetas de mayo» hablan Ángel Battistessa, Juan Carlos Ghiano y Amelia Sánchez Garrido en sus respectivos artículos recogidos en Algunos aspectos de la cultura liferaria de Mayo, La Plata, UNLP, 1961; «poesía de la independencia» la define Fernando Rosemberg en «La poesía de la independencia», en BAAL (Buenos Aires), 1967, XXXII, nos 123124, págs. 203-222.

La construcción de una identidad: el mundo indígena en la literatura independentista (La Lira Argentina) ELENA DE LORENZO ÁLVAREZ 
La numeración romana que acompaña la fecha de publicación en el diario corresponde siempre a su orden en La lira argentina según la edición de la Academia Argentina de Letras ya citada.

12

Sobre este tópico literario y su uso en la poesía española durante la Guerra de la Convención, la de Independencia, el período absolutista y las Guerras Carlistas puede verse Elena de Lorenzo Álvarez, "Las furias de la patria», en Nuevos mundos poéticos: la poesía filosófica de la Iustración, Oviedo, Instituto Feijoo de Estudios del Siglo XVI: (Textos y Estudios del Siglo XVIII, 23), 2002, págs. 397-465.
La construcción de una identidad: el mundo indigena en la literatura independentista (La Lira Argentina) ELENA DE LORENZO ÁLVAREZ como plasmación de la identidad colectiva es un proceso de particularización, que individualiza a determinada comunidad frente a otra a través de la negación -en un principio, sólo somos «lo que no queremos ser»-; al tiempo, ha de generarse un proceso de cohesión de los individuos del grupo, que actúa como unidad frente al resto. La densidad de este proceso de particularización y cohesión identitaria no pivota tanto sobre el espacio, coordenada fundamental para la constitución de un estado, como sobre el tiempo: la «invención» de una identidad reside en el reconocimiento de un pasado común que la mitopoeia compacta y codifica para el recuerdo en un panteón de hombres ilustres emprendedores de grandes hazañas fundacionales; este culto a los antepasados opera además como un nexo presente, que anima la voluntad de un destino colectivo y justifica las razones de actuación conjunta, y también como un legado para el futuro, al que habilita y sobre el que proyecta la imposición de sus deberes. Estas proyecciones temporales del ser nacional y sus compromisos tienen su más acabada cristalización en el verso «somos los que fuisteis, seremos los que sois», el canto épico espartano que Ernest Renan, en la obra no exenta de cierto romanticismo ¿Qué es una nación?, consideraba por su sencillez el himno abreviado de toda patria.

Ahora bien, la independencia constituye precisamente la ruptura de la continuidad histórica y el dislocamiento del pasado inmediato, es decir, de la identidad española. Por tanto, el modelo identitario alternativo ha de orientarse hacia otro pretérito: el mundo precolombino, en cuya resistencia al español encuentra precisamente la justificación de su independencia.

Entre los poemas recogidos en La lira, el que más tempranamente recurre a este motivo es la Silva a las provincias del interior oprimidas (1812; XXVIII"1), de Juan Ramón Rojas, un oficial del ejército insurgente durante el sitio de Montevideo. En la silva, es la diosa Discordia quien insta a las provincias arribeñas a sumarse a la rebelión:

¡Guerra, americano, monstruos temblad, hijos del Inca, guerra! Leed el lema que escribieron con sangre de los monstruos, los Indianos: Aqui bizo gravitar su cetro duro

\section{la horrenda tirania \\ sobre sus infelices moradores; al soplo de la patria revivieron, $y$ un golpe de energía \\ bundió cadenas, pueblos y opresores.}

Todo concurre a dibujar la independencia como una venganza de la invasión primera: los americanos son invocados como herederos de los incas, unos buenos salvajes que vuelven a la vida en esta lucha -«infelices moradores» aquí, «sencillos moradores» de cuyas «inermes manos» arrancó el español el «natural dominio» en la Oda a la Excma. Junta Gubernativa de las Provincias del Río de la Plata (1811; V)-; quien los apela es la furia de la «discordia ominosa» dibujada como una de las erinias, cuyo papel en el mito órfico es restaurar el orden y conminar al respeto de leyes sociales fundamentales: cuando los mortales transgreden estos preceptos, las diosas, despiadadas pero justas, ascienden del Averno para vengar las afrentas. Si en las tragedias griegas las furias persiguen hasta la locura a Alcmaeon, Orestes o Edipo por sus parricidios, en la poesía filosófica española el mito da cuenta de los «males de la patria», especialmente de la guerra en el marco de la invasión francesa, codificándose en el tópico de las «furias de la patria ${ }^{12}$, cuya negativa significación se cierne en esta silva sobre los españoles. De este modo la historia adquiere caracteres míticos: la invasión es interpretada como la trasgresión de una ley divina y la independencia como la represalia a que incita una diosa justiciera por un crimen primero.

La Marcha mexicana y la Canción nacional guaraní (1816; XLIX) son un mismo poema publicado con ligeras variantes en $E l$ Censor y en La prensa argentina, dos periódicos redactados por Antonio José Valdés, a quien se atribuye la autoría. Tanto el poema como su segundo título remiten a un tiempo indígena acorde con el mundo de los independentistas:

¿Qué os detiene patriotas indianos?

[...] Hace tres siglos que pisó la arena de Anahuac el hispano feroz,

[...] pero ingrato a la dulce acogida

que del gran Moctezuma logró,

le aprisiona con negra perfidia

y la muerte le da con traición.

El impío Cortés introduce 
la discordia en la indiana nación

y bien pronto en recíproca guerra,

a la América triste envolvió;

[...]. Mexicanos, abrid ya los ojos,

ahora estáis en igual situación:

[...] Si salvar nuestra patria desea

procurando la paz y la unión,

¿por qué rehúsa adoptar las medidas

que ofreció generoso Rayón?

[...]. Infelices dos veces seremos,

si perdemos la actual ocasión

de romper las infames cadenas,

que esclavizan a nuestra nación.

Si cuando éramos mansos corderos

libertad no gozamos ni honor

¿cuál será nuestra mísera suerte

si llegare a quedar vencedor?

El recibimiento que Moctezuma dispensó a Cortés en la creencia de que era el dios azteca Quetzalcóatl, su apresamiento y muerte reproducen el mítico perfil de Moctezuma como buen salvaje frente a un no menos retórico feroz, pérfido e impío Cortés; el enfrentamiento entre Moctezuma y su sobrino Cuauhtémoc, que pretendía oponerse a los invasores, y la alianza de los españoles con los tlaxcaltecas, grupo nahua amenazado por un imperio azteca en franca expansión, son un muestrario de las «discordias» que separaban a los indígenas, luchas fraticidas de las que se culpa a Cortés y que la Marcha identifica como causa de la derrota. La razón de estas alusiones se justifica en el marco de las disputas criollas entre quienes quieren gobernar en nombre de una monarquía fernandina en manos napoleónicas y los que, como el periodista, apuestan por la revolución. La remisión ejemplar al pasado indígena culmina en el pretérito éramos, que establece una identidad genealógica entre los indígenas que en el pasado eran «mansos corderos» y los belicosos independentistas contemporáneos.

El oriental Bartolomé Hidalgo, más conocido por los Diálogos y Cielitos que inauguran una corriente popular gauchesca recreando el monólogo popular del hombre del campo, festeja en El triunfo (1818; LXII) la batalla de Maipú. En esta obra «unipersonal con intermedios de música», tras la liberación de una «América del Sud encadenada» ante la que los hijos juran «firmeza en la venganza», el actor que recita demanda la presencia de caudillos indígenas:
¡Cenizas inmortales de araucanos,

del sepulcro salid, venid guerreros,

oh, Tucapel, Caupolicán valiente,

cuyos brazos temibles persiguieron

al déspota español con bizarría;

mirad a San Martín que defendiendo

vuestros derechos justos, libre deja

el país más hermoso y más ameno!

El declamador reclama así para un San Martín que dirige las fuerzas chilenas la admiración de los antihéroes de La Araucana de Ercilla. Como en aquélla, la finalidad del instintivo e impetuoso Tucapel y el forzudo Caupolicán no es sino engrandecer por sobrepujamiento a otras figuras: antes Valdivia, en este caso el independentista argentino al que deben agradecimiento como defensor de los derechos indígenas y vengador de su afrenta. Al final del poema Jano, el dios bifronte de la paz y la guerra, abre sus puertas, presentando de nuevo como referencia para los héroes nacionales «bustos indianos, dignos mausoleos».

Dos poetas más recurren a esta imagen: Esteban de Luca y Vicente López y Planes, que forman, junto a Juan Cruz Varela, la tríada de la primera poesía rioplatense. En $A$ la victoria de Chacabuco. Por las armas de las Provincias Unidas, al mando del Excmo. Sr. brigadier Gral. D. José de San Martín (1817; LI), Luca, luchador en las invasiones inglesas y director del arsenal de Buenos Aires, representa al español como una maligna deidad -un Minotauro, un Titán- que acecha en los Andes a Soler, O’Higgins y San Martín - «otro Aníbal más famoso» pues, como el cartaginés, traspasa una cordillera- y salpica con sangre «de la indiana gente» a quien se resiste; por ello, la tierra conquistada clama:
El oprimido suelo
mira en fuertes guerreros convertido:
¡Venganza, Eponamón, venganza y guerra!
[...] Las sombras irritadas
de Tucapel, Caupolicán, Lautaro,
dejaron los patriotas hoy vengadas.
Hoy vuestro nombre caro
llama al hijo de Arauco que la lanza
tiñe en sangre española en la matanza.

Luca hace que una tierra personificada clame venganza al dios Eponamón, la divinidad guerrera por la que los araucanos juran para
La construcción de una identidad: el mundo indígena en la literatura independentista (La Lira Argentina) ELENA DE LORENZO ÁLVAREZ 


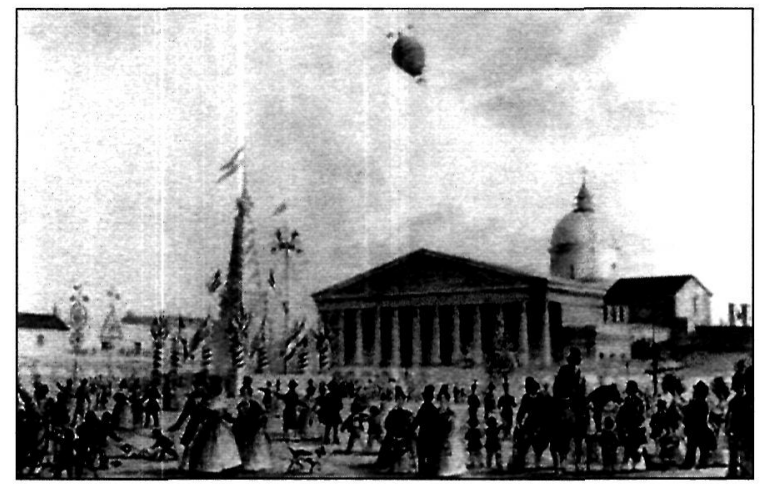

Charles Henri Pellegrini, Plaza de la Victoria y Catedral. Acuarela, 1839. obligarse a cumplir lo que prometen y a la que solicitan ayuda en La Araucana en los momentos graves. Así, el triunfo de Chacabuco queda amparado por deidades indígenas con referencias literarias y legitimado como una revancha con la que 13

Dada su elección como himno nacional y recordando el carácter «monumental» de la Lira argentina, Juan María Gutiérrez en "La Literatura de Mayo», afirma que el poema es, junto a la Pirámide de la Plaza de la Victoria, hoy Plaza de Mayo, el gran monumento de la independencia; recogido en Teoría y crítica de la emancipación hispanoamericana, op. cit., págs.191-202, la cita en la pág. 202.

\section{4}

Emilio Carilla, «Los tres Grandes: Bello, Olmedo, Heredia», en La literatura de la independencia hispanoamericana, Neoclasicismo y Prerromanticismo, Buenos Aires, Eudeba (Biblioteca América. Libros del tiempo nuevo, 25), 1964, 124 págs., el capítulo en las págs. 70-116. Señala CariIla: "La verdad es que, si aparece a menudo en versos patrióticos el recuerdo de los incas, los aztecas y otros antiguos habitantes de América, tal recuerdo constituye más bien un elemento retórico", pág. 26. Enumera otras obras literarias hispanoamericanas en que aparece el tema en la pág. 45.

\section{5}

Andrés Bello, «La agricultura de la zona tórrida», El Repertorio Americano, t. I, Londres, 1826, págs. 7-18; recogido en Obras completas, vol. I, prólogo de Fernando Paz Castillo, Caracas, Ministerio de Educación, 19511957, págs. 65-74, los versos en la pág. 73.

La construcción de una identidad: el mundo indígena en la literatura independentista (La Lira Argentina) ELENA DE LORENZO ÁLVAREZ

«el hijo de Arauco» -esto es, el «nacido» en Chile- sosiega a la canónica tríada de antihéroes épicos vencidos, en cuyo "nombre caro" lucha: Tucapel y Caupolicán, que también menciona Hidalgo, y el ingenioso Lautaro.

$\mathrm{Al}$ año siguiente Luca publica el poema $\mathrm{La}$ secretaría de Estado en el departamento de gobierno del vencedor de Maypo (1818; LVI). Si ya el lugar de la victoria se nomina con grafía indígena, situando este triunfo en el marco de las luchas de resistencia aborigen, además retoma la agresión de Cortés como ofensa primera:
¡Ah! que en su seno
hondamente gravadas permanecen
las atroces heridas, que inundaron
de sangre el trono de los dulces Incas,
de Moctezuma en México opulenta.

Y amalgamando las luchas de tres siglos antes con las criollas presentes es un «indo sacerdote» quien, al zarpar las naos fernandinas de España, augura presagios favorables a los americanos - «consultado el oráculo declara / prodigio tal en pro de los indianos»-; y son «los pacíficos dioses» indígenas quienes se refugian en el «libre Arauco» mientras como «lobo hambriento» el español «se abrasa por destruir la indiana hueste». Ahora bien, el uso del repertorio mítico-literario inca y araucano no es óbice para que el poeta reclame como inspiradora de su poema a Calíope, la musa de la poesía épica, y para que los caídos en la batalla vayan a vivir con «los libres de la antigua Atenas» en los Campos Elíseos, el paraíso prehelénico al que, en las obras de Homero, eran llevados en cuerpo y alma los grandes héroes para hacerlos inmortales.

En la Oda al Sr. D. Antonio Balcarce, coronel de los reales ejércitos, mayor general $y$ vocal de la Junta de Comisión del Ejército Auxiliador (1810; II), López y Planes, que se había alistado en el Regimiento de Patricios durante las invasiones inglesas, había participado activamente en la Revolución de Mayo y era en el momento de composición Secretario de la Junta del Ejército, celebra la victoria de Suipacha en el Alto Perú como la del que «tiene por cuna / el suelo», al que constantemente llama «indiano» -la memoria de la victoria se conservará en «indianos corazones», son los «indianos generosos» los que defienden al oprimido y «los indianos» merecen la fama de la batalla de las Termópilas que Herodoto relató en las Historias-. La genealogía de estos indianos se dibujará en la Marcha patriótica (1813; I), el himno nacional argentino en que se hace revivir el brío de los difuntos héroes incas ante el espectáculo patriótico ofrecido por sus hijos independentistas ${ }^{13}$.

\section{Se conmueven del Inca las tumbas, y en sus huesos revive el ardor lo que ve renovando a sus hijos de la patria el antiguo esplendor.}

De nuevo, en la Loa (1818; LXVI) será el Río de la Plata el que anime a los «valientes hijos de Tucapel y de Lautaro» a pelear en la batalla de Maypo.

$$
* * *
$$

A partir de esta relectura, cabe establecer dos ejercicios intertextuales. Uno, vinculando ese monumento oficial que es La Lira argentina con la poesía de la independencia hispanoamericana: se advierte entonces en La Lira la presencia acabada de ese artefacto retórico en que el épico pasado indígena es seña de identidad ya a partir de 1812, con bastante anterioridad a los siempre citados usos de los dos neoclásicos de «los tres grandes» de la poesía de la emancipación ${ }^{14}$ : el manejo de Andrés Bello en La agricultura de la zona tórrida (1826), en que tras la independencia «saciadas duermen ya de sangre ibera / las sombras de Atahualpa y Moctezuma» y en que el venezolano espera que «si la innata mansedumbre duerme» la paz «la despierte en el pecho americano» ${ }^{15}$ y el tratamiento del ecuatoriano José Joaquín Olmedo en La victoria de Junin. Canto a Bolivar (1825) en que la «venerada Sombra» de Huayna Cápac, el 
último gran emperador inca, se aparece en el campo de batalla vestido con manto y cetro y también con «penacho, arco, carcaj, flechas y escudo», advierte a la «generación del sol afortunada, / que con placer yo puedo llamar mía» de que es llegada la hora de la «venganza y gloria de mi pueblo", llama a Bolívar "predilecto / Hijo y Amigo y Vengador del Inca!» y «Jefe de mi nación», juzga la victoria de Sucre en Ayacucho (1824) -que pone fin al dominio español en América del Sur- «la hora feliz», la edad de oro de una «nueva edad al Inca prometida / de libertad, de paz y de grandeza» y anima a Bolívar a conseguir una unión pacífica que le merecerá el ingreso en el panteón de fundadores de la patria americana, junto a Manco Cápac, el primer Hijo del Sol, fundador de la ciudad de Cusco y protagonista del mito de origen más importante de la tradición inca. El propio Olmedo, presentando las acciones independentistas como el otro polo histórico de la resistencia indígena, en $\mathrm{Al} \mathrm{Ge-}$ neral Flores, vencedor en Miñarica (1835) señala que la musa de Junín «de los Incas deifica la memoria, / y a sus manes sagrados / si tumba les faltó, levanta altares» ${ }^{16}$.

El otro ejercicio interdiscursivo obligado es la relación de La lira argentina con la epopeya. La invocación a las musas -especialmente a Calíope-, la intervención de fuerzas sobrenaturales indígenas -al modo de las que Tasso había cristianizado en la Jerusalén liberada-, las descripciones bélicas, la actuación de personajes colectivos, la abundancia de parlamentos, la recitación pública a que están destinadas, los abundantes coros, la trompa de la fama que adorna el emblema de la edición de 1824, todas estas referencias evidencian que lo que llamamos poesía «patriótica», tanto para la literatura española como para la hispanoamericana de finales del siglo XVIII y principios del XIX, es en esencia poesía épica, la actualización de aquellas epopeyas que mantienen la memoria de acontecimientos fundacionales convirtiéndolos en hazañas legendarias de períodos históricos cruciales en que bien se revela la necesidad de afianzar una identidad -como en el caso español frente a la invasión napoleónica- bien de construirla -como en el caso argentino frente a España-. Claramente lo demuestran las constantes llamadas a La Araucana, el gran poema épico de la conquista al que precisamente Hellén Ferrero considera «un primer germen de la poe- sía patriótica futura» en virtud del encomio común de aquel que defiende «una libertad justa» ${ }^{17}$. Del mismo modo que el reconocimiento de valores épicos como la nobleza, dignidad y grandeza del enemigo derrotado, que bien pueden resumirse en el aserto de Galvarino «muertos podemos ser, mas no vencidos», le sirve a Ercilla para engrandecer por sobrepujamiento a los que finalmente consiguieron sobrepasar a aquellos indígenas convirtiéndose en conquistadores, los poemas épicos independentistas, que serían un contracanto de aquella epopeya de la conquista, benefician a sus actores con aquella legendaria imagen de resistencia del mundo indígena, construyéndolos como dignos herederos de tan preclaros ancestros con los que se comparte enemigo, y dibujando una nueva identidad para el recientemente emancipado individuo americano.

En el plano ideológico, esta formulación e idealización de los acontecimientos recientes en virtud de un mundo indígena que solicita, legitima y aplaude la acción independentista, cuenta con abundantes referentes inmediatos: aquellas rebeliones del siglo XVIII que invocan míticos nombres prehispánicos, como la de Juan Santos Atahualpa (1742-1761) o la de José Gabriel Condorcanqui, «Túpac Amaru» (1780-1781), o nominaciones como Logia Lautaro (1811) que eligiera una rama de la Gran Reunión Americana de Londres o Logia de los Caballeros Racionales fundada por Francisco de Miranda en $1798^{18}$.

Por otro lado, se advierte en estos poemas la ausencia poética del indio coetáneo, cuya presencia únicamente refleja El triunfo argentino (1808; CXXXI); como señala José Carlos Rovira, y en el marco identitario de esta lectura, el poema funciona como una «afirmación histórica» en ese momento de «extensión de un sentimiento criollista» previo a la independencia generado por la expulsión de la armada inglesa ${ }^{19}$. López y Planes describe el ejército que defiende la ciudad de los invasores:

¡Oh, ínclito Señor! Esta no es tropa:

Buenos Aires os muestra allí sus hijos: allí está el labrador, allí el letrado, el comerciante, el artesano, el niño, el moreno y el pardo; aquestos sólo ese ejército forman tan lucido.

[...] El castellano y diestro vizcaíno, el asturiano y cántabro invencible,
16

José Joaquín Olmedo, Poesías completas, texto, prólogo y notas por Aurelio Espinosa Pólit, México, Fondo de Cultura Económica (Biblioteca Americana. Literatura moderna. Poesía), 1947 (Quito, 1945), págs. $122-152$ y 176 184.

17

Hellén Ferrero, Historia de la poesía hispanoamericana, New York, Las Américas Publishing CO., 1964, pág. 24

18

En esta sección, que configurada en Cádiz en 1811 pasa a Buenos Aires en 1812, se insertan Carlos de Alvear, José de San Martín, Juan Martín de Pueyrredón, y fray Servando Teresa de Mier, con el objetivo de propiciar la independencia de la América Española y establecer un sistema republicano unitario con gobierno unipersonal.

19

José Carlos Rovira, «Medina reconstruye la literatura de un episodio: la reconquista de Buenos Aires (1807)», en José Toribio Medina y su fundación literaria y bibliográfica del mundo colonial americano, Santiago de Chile, DIBAM, Centro de Investigaciones Diego Barros Arana (Colección Sociedad y Cultura, XXIX), 2002, págs. 100-107, las referencias en las págs. 100 y 106. En ese capítulo, Rovira comenta los poemas que sobre este acontecimiento recuperó Medina; en el CD Nuevos textos para la literatura hispanoamericana colonial, Alicante, Publicaciones de la Universidad, 2000, se reproducen todos los poemas, que también pueden encontrarse en la Biblioteca Virtual Miguel de Cervantes (wnw.cervantesvirtual.com).

La construcción de una identidad: el mundo indígena en la literatura independentista (La Lira Argentina) ELENA DE LORENZO ÁLVAREZ 
Habrá que esperar hasta 1870 , cuando Mansilla publique su Excursión a los indios ranqueles, presentando al ranquel como un "otro" comprensible, productor de cultura y susceptible de ser incorporado al proceso de civilización, cuestionando el estereotipo de civilización y barbarie y respondiendo a la política sarmientiana, que desestima la posible transculturación del aborigen $y$ en consecuencia tiende a su aniquilación y sustitución por nuevos contingentes inmigratorios.

21

Pedro Luis Barcia, «Estudio preliminar», op. cit., págs. LXXVILXXVIl y LXXIX. Para la definición de indianismo e indigenismo véase Antonio Cornejo Polar, «La novela indigenista: una desgarrada conciencia de la historia», en Sobre literatura y crítica latinoamericanas, Caracas (Universidad Central de Venezuela), 1982, e Indianismo e indigenismo en América, edición de José Alcina Franch, Madrid, Alianza (500 años), 1990.

\section{2}

Evidentemente, la información demográfica del censo es relativa, pues indica los tantos por ciento únicamente de la población que vive en el marco de la sociedad colonial, pero ésta es ahora la que nos interesa. Véase Elena Studer, La Trata de negros en el Río de la Plata durante el siglo XVIII, Buenos Aires, 1958; Guillermo Beatro, La época colonial entre los años 1600 y 1750 , Historia Argentina. De la conquista a la Independencia, Buenos Aires, Paidós, 1972; George Reid Andrews, Los afroargentinos de Buenos Aires, Buenos Aires, De la Flor, 1990.

\section{3}

Para el caso argentino, el fenómeno del criollismo identitario comienza con el Juan Moreira (1880) de Eduardo Gutiérrez, que sube a las tablas con los hermanos Podestá (1886) alumbrando un teatro "argentino» frente a la atónita y escandalizada mirada de la oligarquía. Pero, en la medida en que el criollismo va convirtiéndose en vía

La construcción de una identidad: el mundo indigena en la literatura independentista (La Lira Argentina) ELENA DE LORENZO ÁLVAREZ

el constante gallego, el temible hijo

de Cataluña, el arribeño fuerte

y el andaluz se prestan al conflicto;

los pardos, naturales y morenos

pruebas dan de lealtad y patriotismo.

[...] $¡ \mathrm{Oh}$, vosotros iberos, oh argentinos,

que de Roma y Cartago sois afrenta

[...] para que el anglo en cuanta lid intente

humille su cerviz al argentino.

Previamente a la independencia los «naturales» pueden compartir un mismo plano de contemporaneidad con peninsulares, arribeños -de las provincias del norte de Buenos Aires-, pardos y morenos ${ }^{20}$. Sin embargo, la mentalidad independentista los disocia plenamente del indio lejano en el pasado. Por esta evocación distante, la recreación del mundo indígena en esta poesía-que no puede ser interpretada como «indigenismo», pues su mirada carece de toda perspectiva social y política contemporánea-, suele definirse como «indianismo»: el manejo propio de la literatura colonial que idealiza a un indio remoto en el pasado ${ }^{21}$.

Tal clasificación literaria no explica, sin embargo, la razón del decidido empeño de disociación entre los indígenas contemporáneos y sus ancestros, y la presencia contemporánea indígena previa a la independencia y su desaparición posterior en favor de un tipo literario respaldado por el aparato épico cultural. Probablemente, la realidad indígena palpable resulta angustiosa y amenazadoramente próxima, además de que impide el asentamiento de establecimientos fronterizos en los terrenos «vacíos», siendo estas fundaciones imprescindibles para la extensión de la campaña

de ideas libertarias de procedencia europea -Alberto Ghiraldo difunde en Alma Gaucha (1907) el ideario anarquista-, la elite conservadora y liberal, que había intentado otra literatura nacional, otra forma de identidad, durante décadas, terminará aceptando este dispositivo cultural en tanto resulta apropiado para el discurso nacionalista estatal ofreciendo un sistema de representación aparentemente abarcador $y$, por ello, semi-totalitario. El criollismo nacionalista conservador sirve a la oligarquía terrateniente como arma ideológica contra una agitación proletaria cuyos dirigentes des- bonaerense, que se intenta desde fines del siglo XVIII pero se convierte en necesidad perentoria a partir de la independencia, cuando se comienza a perfilar la necesidad de una unidad geográfica nacional; finalmente, ya se ha señalado que el proceso de conformación de un ser nacional se ancla en el pasado, por lo que es lógico que el poeta independentista que quiere dibujarse a sí mismo como vengador de épicos héroes indígenas «desaparecidos» remita a aquel indio lejano que puede proporcionarle un linaje y calle la existencia de sus verdaderos descendientes genealógicos.

En el mismo sentido y en el marco de construcción de una nueva identidad, este silencio se conjuga con el mutismo sobre el otro grupo contemporáneo que podría haber constituido la raíz identitaria: el africano. El censo argentino de 1778 constata que es negro el $60 \%$ de la población de Córdoba (entonces con 44.052 habitantes), el $28 \%$ de la de Buenos Aires (entonces con 24.363 habitantes), el $64 \%$ de la de Tucumán, el $54 \%$ de la de Santiago del Estero, el $52 \%$ de la de Catamarca y el $46 \%$ de la de Salta ${ }^{22}$. Pero de poco sirve esta presencia demográfica, pues el «negro», «mulato», «zambo», «pardo», «moreno», «cuarterón», «bozal», «criollo», «liberto» o «cimarrón», según genética, nacimiento y situación social, pero siempre «pieza de Indias» de la Trata negrera que dinamizó la economía del virreinato, ni es aborigen ni abunda como personaje literario, por lo que su reconocimiento genealógico no conlleva el derecho de tenencia a la tierra ni engrandecimiento alguno.

En este contexto histórico contemporáneo, el independentista criollo prefiere afianzar su identidad dibujando como prestigiosos y retóricos ancestros a caciques indígenas de otras zonas americanas desaparecidos tres siglos atrás. Y, cuando el criollismo argentino se vuelva hacia el presente, renunciará a pampas, patagones y comechingones, $y$ afirmará su diferenciación construyendo el icono nacional de un gaucho en enfrentamiento constante con la autoridad pero también con el indígena, una figura paralela del llanero de Venezuela, el sertanejo en Brasil o el huaso de Chile, sobre los que igualmente se vierte, como veía Borges en El escritor argentino y la tradición, la mirada ajena, plagada de camellos, de "un falsario, un turista, un nacionalista ${ }^{23}$. 
Dados estos silencios, y en el marco de creación de una identidad que legitime el nacimiento político de la nueva nación, más que «indianismo», más que «recuperación» o «reconstrucción» literaria del mundo indígena, encontramos en La lira argentina la construcción literaria de una «visión del pasado» acorde con el proyecto político de configuración de un Estado, que responde a un nacionalismo en busca de identidad que encuentra en el indio su mítico héroe legitimador. Se re-escribe la resistencia indígena al colonizador como un contracanto de la épica de la conquista, vertiendo aquellas lejanas glorias sobre sus propias luchas emancipadoras presentes, que resultan legitimadas y prestigiadas, para perfilar una genealogía y remitir a un agravio primero que justifique el derecho a una independencia dibujada como la recuperación de un remoto pasado arrebatado. Por tanto, los po- emas hablan más de aquello a lo que el criollo aspira que del indígena mismo: el verdadero núcleo imaginario del motivo indígena en $L a$ lira argentina no es el indio -ni el contemporáneo ni el distante en el tiempo-, sino la construcción y el elogio del sujeto independentista contemporáneo en función del objeto indígena evocado.

La literatura de mayo es una enunciación privilegiada de la construcción de la nación, un ejercicio de «imaginación retrospectiva» cuyo fin es la invención de un linaje, un complejo artefacto del nacionalismo intelectual que proporciona legitimación política y contribuye a lo que Roland Barthes definía como el funcionamiento esencial de la ideología: vivir como natural lo que es histórico, vivir como esperada venganza indígena y como lógico y legítimo destino el Estado que una elite de españoles americanos está forjando. 